INTERNATIONAL HIGHER EDUCATION NUMBER 65 FALL, 2011 Pages $7-10$

Is There a Future for Branch Campuses?

Philip G. Altbach

Philip G. Altbach is Monan professor of higher education and director of the Center for International Higher Education at Boston College.

Branch campuses seem to be the flavor of the month or, perhaps, the decade. Universities, mostly but not exclusively from the developed and mainly Englishspeaking countries, have established overseas branches worldwide-mainly in developing and emerging economies. The Observatory on Borderless Higher Education counted 162 branch campuses in 2009, with American universities accounting for 48 percent of the total. No doubt, the number of branches has increased significantly since then. The Arabian Gulf has received a great deal of global attention since several countries have welcomed-and paid for-branch campuses, as part of their higher education growth strategies. For example, Education City in Doha, Qatar, currently hosts six American universities and one from Britain. Bahrain, the United Arab Emirates, and other Gulf countries have additional branch campuses of foreign universities. Singapore predates the Gulf as a higher education hub.

Given this boom in branches, several fundamental questions need to be raised: what are branch campuses? Are they sustainable over time? What unique service do they render to students and the academic community? 


\section{WHAT IS A BRANCH?}

There is no generally accepted definition. Most observers seem to agree that an "international branch campus" is an entity pertaining to a university whose primary location is in one country, which operates in another and offers its own degree in that country. Upon successful completion of the course program, fully undertaken at the unit abroad, students are awarded a degree from the foreign institution. This definition excludes joint-degree programs, twinning arrangements, overseas campuses serving students from the home university, degree franchising, and other international ventures. In a few cases, branch campuses offer the opportunity for students at the branch to study at the home university for part of their program, and some offer "study abroad" facilities for students from the home campus.

This simple definition must be considered in a fundamental way. Are the students at the overseas campus receiving essentially the same educational experience as they would experience on the home campus? Is the quality of instruction equivalent? Are the professors from the home campus? Are the facilities broadly equivalent-taking into account that it would be impossible to duplicate New York's Washington Square campus in Abu Dhabi? In other words, is a student experiencing the same, or close to the same, education as at the home campus? It is not enough to put a university's name on the degree. The actual quality and at least a semblance of the academic experience and culture at the home campus must be provided for a branch campus to deserve to offer a university's degree. Anything less "dilutes the brand" and should not be called a branch. 


\section{QUESTIONS OF SUSTAINABILITY}

With a few exceptions, branch campuses have been established fairly recently, so that there are few clear lessons to be drawn yet from limited experience. Still, a number of questions concerning sustainability must be asked.

Enrollments. Will branch campuses be able to enroll students of the same quality as their home-campus students over time? A number of problems in this respect are already evident. The University of New South Wales, for example, closed its branch campus in Singapore in 2007, after less than a year-due to low enrollments. Most of the American branches in the Gulf are reportedly under enrolled. In that region, particularly, it is unclear whether there are a sufficient number of young people with the requisite interests and academic accomplishments fill the existing branch campuses, not to mention new ones.

Some of the branches see possibilities for enrollment from the Indian subcontinent, with its large population of underserved students. Yet, a recent survey showed that prospective Indian students prefer to study in the United States rather than at an American branch campus in the Gulf or, for that matter, in India itself. They would like the full experience of American culture and, perhaps, the possibility of staying in the United States to work following graduation. However, studying at a branch campus provides neither of these opportunities. Data from China indicate that students are not willing to pay USlevel tuition at branch campuses of American universities in China, and they worry about the quality of faculty and programs.

Branch campuses in the Gulf are counting on significant numbers of female students from the region, assuming that many families will not want to have their daughters studying in the West but would prefer a regional 
institution-although 21 percent of Saudi Arabian students abroad, largely in Western countries, are women. Clearly, the assumptions are faulty. Furthermore, the small population base in the Gulf means that the numbers of students with high-academic qualifications are limited. To make matters even more complicated, both the branch campuses and local universities often need to provide up to a year of preparatory study for many students before full admission is possible-due to a combination of inadequate English-language skills and inadequate secondary school preparation. For selective universities, like Carnegie Mellon or New York University, it is highly questionable whether the pool of qualified candidates will be large enough to become sustainable over time.

While hard data are impossible to obtain, some reports have revealed that most branch campuses have not as yet met enrollment targets. Enrollments are hard to predict and depend on many variables, including changing political and social circumstances. It is not clear how the current unrest in the Middle East will impact the branch campuses in the region. As more branch campuses are established in educational hubs worldwide, there will be increased competition among them.

Faculty and staff. A branch campus requires home campus faculty to provide a real academic experience of the sponsoring university. This does not mean a few faculty members just fly in for "intensive" weekend courses. Will branch campuses be able to lure faculty members, for a semester or longer, from the home to an overseas campus? Residential faculty are necessary. Moreover, temporary adjunct faculty located in the region or local residents with doctorates awarded by the main campus of the university will not suffice. Home campus 
faculty must be willing to teach at the branch for a year or more. Again, the idea of a branch campus is to replicate the academic and other experience of the home university. Similarly, key administrators and support staff in student affairs and other areas must belong to the home campus to provide the spirit of the home university or at least have experience at the home campus.

Experience shows that it is quite difficult to convince home campus faculty to teach in an overseas branch campus for extended periods of time, even when salary and other benefits are attractive. Yet, even once the small group of internationally minded faculty and staff have volunteered to go abroad, convincing others to go is all but impossible. Uprooting working spouses and children is not easy. Research-active faculty-especially in the hard sciences, where laboratories at the branch cannot match those at home-will also be reluctant to leave their labs.

Funding. Branch campuses of prestigious universities receive generous start-up funding from host countries, institutions, property developers, or other entities. Typically, little up-front investment is provided by the home university and in some cases, such as the Gulf, hefty subsidies. However, significant nonmonetary expenses include the time spent by a myriad of administrators and faculty for planning, negotiations with host governments and institutions, and other aspects. Developing curricula, implementing personnel policies, and working with a variety of stakeholders all involve time-and, indirectly, money.

Sustained funding as the branch campus develops is another challenge. Most universities do not want the branch to be a drain on home campus resources, and indeed some institutions expect overseas ventures to earn a profit. For public universities, legal requirements on public funds are an added 
challenge, given restrictions on spending public funds overseas. Branch campuses may be under considerable pressure to "break even" quickly. Where there are sponsors with deep pockets, as in the Gulf, pressures will be less intense, but the branch campuses will eventually need to be financially sustainable.

While there are little if any data available, it seems that the most financially successful branch campuses are those sponsored by less-prestigious universities and other educational providers, which offer programs that are inexpensive to provide and have a ready interest abroad. Quality standards are often low, and careful attention is given to the "bottom line," with little regard for local relevance.

A quality-branch campus, even if it is small and specialized, requires careful financial planning in a context, which includes many variables that are difficult to measure or predict. The cost of coordination and administration at the home campus, direct instruction, maintaining appropriate enrollment and income levels, and other variables are extraordinarily difficult to forecast.

\section{ACADEMIC FrEedom}

Worries have been raised about academic freedom at branch campuses. Although key leaders and relevant agreements guarantee academic freedom, many faculty are worried. What happens, some say, if a faculty member at a Dubai branch invites an Israeli speaker, or one in China invites the Dalai Lama or writes an op-ed highly critical of the authorities. How will authorities in countries without a stellar academic freedom record handle the branch campuses? 


\section{Home Campus Politics}

Branch campus initiatives are typically proposed by top university management and not by the faculty or students. They may be seen as a way of boosting the university's global image, contributing to internationalization, earning income, or a way to address other institutional strategic goals. The larger academic community is seldom involved in either planning or executing the branch campus initiative. Indeed, it is often hard to convince the faculty and students that branch campuses are worth the additional work, risk, and commitments required. Without faculty "buy in," success is difficult. Reports of significant campus grumbling at New York University have been published, and campus opposition was cited as one of the reasons for the failure of Michigan State University's branch campus in the Gulf. Most recently, criticism at Yale University concerning that university's partnership with the National University of Singapore, due to concerns about academic freedom and other issues has emerged in the media. International ventures have frequently been subject to considerable complaints in Australian universities as well, with members of the academic community criticizing commercial motivations and opposing straying from the university's core academic mission. Press reports concerning virtually all branch campus initiatives have featured disputes between administrators and segments of the faculty.

\section{Overseas Uncertainties and Changing Policies}

The 21st century is the age of globalization. It is also an era of political instability and the transformation of national policies and priorities in many parts of the 
world. Branch campuses operate in a national context. The current Arab Spring political and social unrest is an example of how drastically and unpredictably political circumstances change. It is impossible to know how the political and social transitions in the Middle East will affect branch campuses in the medium and long run.

The current debate in India—one of the world's largest potential student markets-about government policies relating to branch campuses and other foreign higher education initiatives-is yet another example of how unpredictable this environment can be. The terms and conditions of international involvement will be dramatically altered; and the practical aspects of how these policies will be implemented, in a country famous for opaque regulations, will only emerge over time. Branch campuses are vulnerable to changing and sometimes unstable environments.

\section{DIFFERING EXPECTATIONS}

Experience shows that at times conflicting expectations of the sponsoring university and the host country or sponsor can result in serious problems. Contractual agreements may be interpreted alternatively—sometimes leading to conflicts among participating parties or even the closure of the branch. A number of these conflicts resulting from differing or interpretations of agreements are, even in this early stage of the branch campus phenomenon, already evident. The problems may be exacerbated when one side-usually the host country-is investing the bulk of the funds. 


\begin{abstract}
A Bubble?
Obviously, numerous and fundamental problems are facing branch campuses. Even if the basic concept is viable, the risks are substantial. If one accepts the enthusiastic comments and the range of plans and start-ups, there may be a bubble in the making. A necessary episode to recall is that 20 or more American universities rushed to Japan in the 1980s to start branches, but only 2 survived. Exactly the same kinds of misunderstandings, insufficient advance planning, unrealistic expectations on both sides, and cross-national confusion that can be seen today led to the failure of most of the Japanese ventures.
\end{abstract}

The lesson-caveat everyone! 